\title{
The influence of ethanol on the convective drying and on the nutritional quality of dekopon slices
}

Mello-Junior, R. E. ${ }^{\text {** }}$; Resende, N. S. ; Corrêa, J. L. G. ${ }^{\text {a }}$; Pio, L. A. S. ; Carvalho, E. E. N. ${ }^{\mathrm{a}}$

${ }^{\text {a }}$ Department of Food Science. Federal University of Lavras, Minas Gerais, Brazil.

${ }^{\mathrm{b}}$ Department of Agricultural. Federal University of Lavras, Minas Gerais, Brazil.

*E-mail of the corresponding author: ronaldo_uba@hotmail.com

\begin{abstract}
Dekopon or Hallabong (Citrus reticulate "Shiranui") is a hybrid fruit that belongs to the citrus fruits. The scientific and commercial interests in dekopon is due to its nutritional composition. The objective of the study was to verify the influence of ethanol as a pretreatment in reducing drying time as well as maintaining nutritional quality (vitamin $C$, total phenolic compounds, and antioxidant activity) of dekopon slices. The drying with ethanol at $70{ }^{\circ} \mathrm{C}$ promoted the greatest reduction in drying time, but the processed pretreated samples at $50{ }^{\circ} \mathrm{C}$ presented the highest level of nutritional quality parameters.
\end{abstract}

Keywords: drying time; vitamin C; phenolic compounds; antioxidant activity. 


\section{Introduction}

The vitamin C, consisting of ascorbic and dehydroascorbic acid, is widely found in fruits and foods, being characterized by its instability to technological processes ${ }^{[1,2]}$. There are also other health-promoting substances, such as phenolic compounds, which are secondary metabolism in plants that have been identified as major antioxidants in fruits ${ }^{[3]}$. Those compounds are present in the fresh form of fruits and vegetables, especially in citrus fruits. Dekopon (Citrus reticulata "Shinarui”) is among the citrus fruits. It is a cross between Kiyomi (Citrus uses Marcov. x Citrus sinensis Osbeck) and Ponkan (Citrus reticulata Blanco). The commercial value of dekopon is due to its sweet taste and pleasant aroma ${ }^{[4,5]}$.

Generally, fruits and vegetables in their fresh form show high moisture content and water activity, providing high degradation rates which may cause significant postharvest losses. To minimize these effects, various processing techniques can be used, as drying. Convective drying is a simple but time consumer process with consequent high energy demand. High temperatures reduce the drying time, but could carry out to food quality and nutritional composition reduction ${ }^{[6]}$. In order to minimize the negative effects of drying, some pretreatments such as ultrasound ${ }^{[7]}$, osmotic dehydration ${ }^{[8]}$ and ethanol application in the environment and on the surface of the samples are commonly used ${ }^{[9,10]}$.

The aims of this work were to (i) investigate the effects of the immersion of the samples in ethanol on drying time, (ii) examine the influence of ethanol and drying temperature on phenolic compounds content, vitamin $\mathrm{C}$ and antioxidant activity.

\section{Materials and Methods}

\subsection{Sample preparation}

Dekopon (Citrus reticulata "Shinarui") were selected based on uniform maturation characteristic with peel color. The fruits were washed and sanitized with sodium hypochlorite solution ${ }^{[11]}$ and stored at $7^{\circ} \mathrm{C}\left( \pm 2^{\circ} \mathrm{C}\right)$ until the beginning of each experiment. The moisture content of the fresh dekopon (method 934.06, AOAC (2005)) was 5.92 \pm 0.01 $\mathrm{kg} \mathrm{H}_{2} \mathrm{O} \mathrm{kg}^{-1}$ d.b.

For the experiments, the samples were peeled manually, eliminating the edges of the fruit. Samples were sliced with the aid of a stainless steel knife and a cutter so as to standardize the size of the slices. After cutting, the dekopon slices presented standardized dimensions $3.27 \pm 0.32 \mathrm{~mm} \times 60.54 \pm 1.12 \mathrm{~mm}$ (thickness $\mathrm{x}$ diameter) and were measured using a digital caliper (Western, DC-60 model, Zhejiang, China). 


\subsection{Convective drying}

The convective drying was performed in a tunnel dryer (Eco Engenharia Educacional, MD018 model, Brazil) The mass variation of samples during the drying was monitored using a digital balance (Marte Científica, AD33000 model, Brazil) (accuracy $\pm 0.01 \mathrm{~g}$ ) coupled to the sample holder allowing to obtain the kinetics of drying. In each experiment, $145.113 \pm 5.862 \mathrm{~g}$ of fresh fruits (totaling five slices) were dried. The process was performed until an average final moisture content of $0.235 \pm 0.054 \mathrm{~kg} \mathrm{H}_{2} \mathrm{O} \mathrm{kg}{ }^{-1}$ d.b.

The drying process followed a 2x2 factorial design to study the effects of air temperature variation (50 and $70{ }^{\circ} \mathrm{C}$ ) ${ }^{[11]}$ and the immersion or not of the samples in ethanol, as a pretreatment. Air velocity was keep at $2.00 \mathrm{~m} \mathrm{~s}^{-1}{ }^{[12]}$. Pretreatment samples were completely immersed in $95 \%$ ethanol in a petri dish for $10 \mathrm{~s}^{[13]}$ in a ratio sample/ethanol of 1:1 (weight/weight) approximately. The moisture content of the dried dekopon was determined according to the AOAC (2005). The water activity $\left(a_{w}\right)$ determination was performed in a hygrometer (Aqualab, 3-TE model, Decagon Devices, Inc., Pullman, WA, USA).

\subsection{Quality analysis}

The total phenolic compounds were quantified using an adaptation of the method of FolinCiocalteau. Quantification was performed by spectrophotometer reading at $750 \mathrm{~nm}$ and the results expressed in mg of gallic acid. $100 \mathrm{~g}^{-1}$ dry matter ${ }^{[14]}$.

The ascorbic acid (vitamin C) determination was performed by the colorimetric method, 2,4 dinitrofenilhidrazina ${ }^{[15]}$ and the results expressed as \% retention of ascorbic acid in the dry product, according to Eq. 1

$$
\text { \%retetntion }=\left(\frac{\mathrm{g} \text { ascorbic ácid in the dehydrated sample }}{\mathrm{g} \text { ascorbic ácid in the fresh sample }}\right) * 100
$$

The total antioxidant activity (AAT) by DPPH (2,2-diphenyl-1-picrylhydrazyl) ${ }^{[16]}$. The results are expressed as \% sequestration. The percentage of sequestration expresses the ability of the food to inhibit the action of the reactive species present in the DPPH radical.

\subsection{Statistical analysis}

All analytical determinations were performed in triplicate. Parameter values are expressed as the means \pm standard deviation. The results were analyzed using analysis of variance 
(ANOVA) and the Tukey test at 5\% significance to compare the mean values using Statistic (Statsoft, Tulsa, USA).

\section{Materials and Methods}

\subsection{Convective drying}

The Fig. 1 shows the evolution of drying of dekopon slices treated and unpretreated with ethanol, at 50 and $70{ }^{\circ} \mathrm{C}$. The drying time for the pretreated fruits to reach a final moisture content of $0.235 \pm 0.051 \mathrm{~kg} \mathrm{H}_{2} \mathrm{O} \mathrm{kg}{ }^{-1}$ d.b was $300.33 \pm 0.95$ and $1193.33 \pm 0.64$ min for 70 and $50{ }^{\circ} \mathrm{C}$ respectively. For the untreated samples the total drying time was $343.33 \pm 0.91$ and $1540.00 \pm 0.83 \mathrm{~min}$ for 70 and $50{ }^{\circ} \mathrm{C}$ respectively.

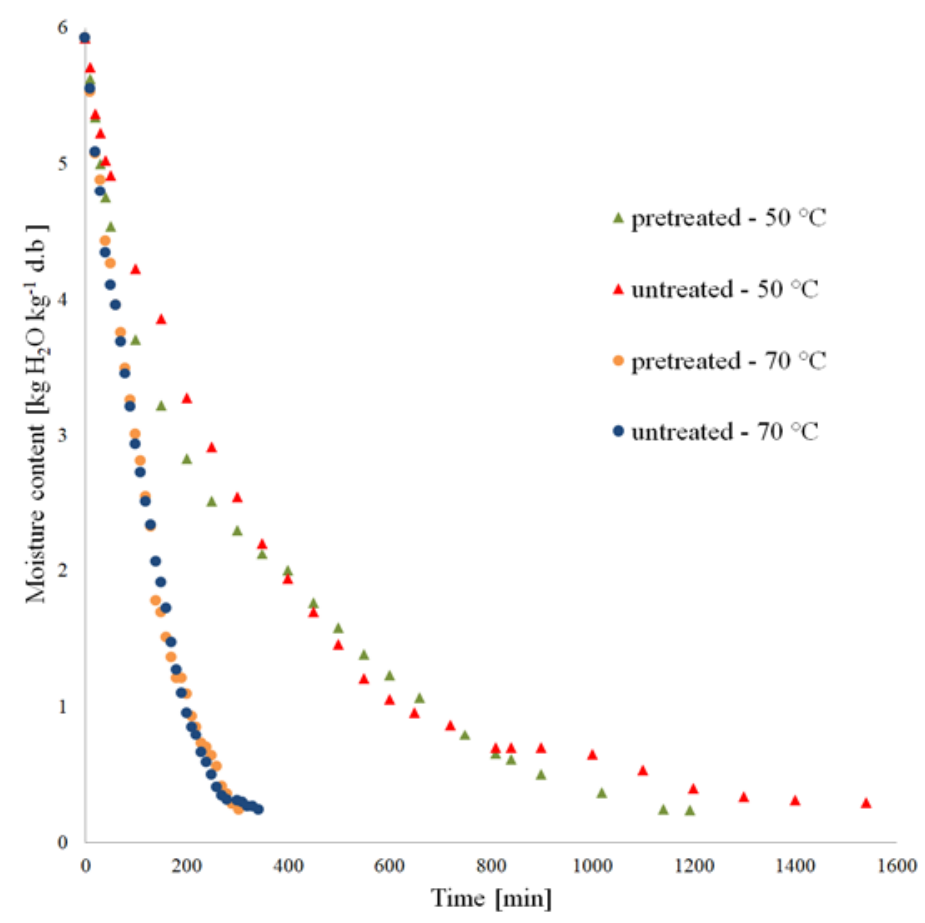

Fig. 1 Evolution of moisture content of treated ethanol immersion and untreated dekopon at 50 e $70{ }^{\circ} \mathrm{C}$.

The experiments at $70{ }^{\circ} \mathrm{C}$ with pretreatment and without pretreatment did not obtain a significant difference between them ( $>0.05$ ), presenting times of $303.33 \pm 2.49^{\mathrm{a}}$ min and 
$343.33 \pm 2.65^{\mathrm{a}} \mathrm{min}$, respectively. However, these experiments differed statistically from the others $(\mathrm{p}<0.05)$, in addition, the experiments at $50{ }^{\circ} \mathrm{C}$ with pretreatment and without pretreatment showed a statistical difference between them $(\mathrm{p}<0.05)$, reaching a final processing time of $1193.33 \pm 3.46^{\mathrm{b}} \mathrm{min}$ and $1540.00 \pm 1.73^{\mathrm{c}} \mathrm{min}$. These data demonstrate the effectiveness of the application of ethanol to the samples of dekopon slices as well as the increase of the drying air temperature with respect to the reduction of the total process time, which can bring benefits mainly in the energy economy. The use of ethanol in direct contact with the sample, as pretreatment to convective drying, was studied by ${ }^{[10]}$ during the drying of banana having the same effect in relation to the increase of the diffusivity allowing the pretreated experiments to present a lower drying time. With the application of the ethanol under the sample, a homogeneous mixture is formed (ethanol has hydroxyl that binds with water by hydrogen bond) and this mixture presents a higher vapor pressure when compared to the solution without ethanol, justifying the reduction of the drying process ${ }^{[10}$, 11, 17]. As the temperature of the air increases, a higher rate of drying occurs due to the greater mobility that the water reaches inside the pores, reducing the internal resistance to the transport of moisture ${ }^{[7]}$, and similar results are found in the literature ${ }^{[18,19] .}$

The $\mathrm{a}_{\mathrm{w}}$ is an important parameter in food preservation and the results have proved the efficiency of the drying process in reduced the values. The fresh samples presented $\mathrm{a}_{\mathrm{w}}$ of $0.97 \pm 0.02^{\mathrm{a}}$, differing from the others $(\mathrm{p}<0.05)$. The experiments at $50{ }^{\circ} \mathrm{C}$ with pretreatment, and without pretreatment, as well as those of $70{ }^{\circ} \mathrm{C}$ with pretreatment and without pretreatment, presented $\mathrm{a}_{\mathrm{w}}$ of $0.36 \pm 0.05^{\mathrm{b}}, 0.37 \pm 0.03^{\mathrm{b}}, 0.38 \pm 0.05^{\mathrm{b}}$, and $0.360 \pm 0.021^{\mathrm{b}}$ ( $>0.05$ ), respectively, according to literature ${ }^{[20] .}$

\subsection{Quality analysis}

The effect of air temperature drying and ethanol immersion on the phenolic content, vitamin $\mathrm{C}$ retention and total antioxidant activity of dekopon slices dehydrated are showed in Table 1.

Table 1. Phenolic content, vitamin C retention and total antioxidant activity in dekopon slices dehydrated

\begin{tabular}{lccc}
\hline \multicolumn{1}{c}{ Conditions } & $\begin{array}{c}\text { Phenolic } \\
\text { [mg 100 } \mathbf{~ g}^{-1} \text { ] }\end{array}$ & $\begin{array}{c}\text { AAT } \\
\text { [\%sequestration] }\end{array}$ & $\begin{array}{c}\text { Vitamin C } \\
\text { [\%retention] }\end{array}$ \\
\hline $50^{\circ} \mathrm{C}$, pretreated & $766.67 \pm 10.25^{\mathrm{a}}$ & $74.80 \pm 0.12^{\mathrm{a}}$ & $39.09 \pm 0.91^{\mathrm{a}}$ \\
$50^{\circ} \mathrm{C}$, untreated & $642.89 \pm 6.14^{\mathrm{b}}$ & $59.06 \pm 1.14^{\mathrm{b}}$ & $32.45 \pm 0.04^{\mathrm{b}}$ \\
$70^{\circ} \mathrm{C}$, pretreated & $622.16 \pm 6.06^{\mathrm{bc}}$ & $51.71 \pm 0.59^{\mathrm{c}}$ & $30.71 \pm 0.03^{\mathrm{c}}$ \\
$70^{\circ} \mathrm{C}$, untreated & $609.75 \pm 4.77^{\mathrm{c}}$ & $49.54 \pm 0.80^{\mathrm{d}}$ & $28.85 \pm 0.09^{\mathrm{d}}$ \\
\hline
\end{tabular}

Different letters mean significant difference $(\mathrm{p}<0.05)$. 
The reduction of bioactive compounds in foods and the degradation of phenolic are usually pointed as drying disadvantages. The lowest phenolic compounds, percentage of retention of vitamin $\mathrm{C}$ and total antioxidant activity were found in the experiments at $70{ }^{\circ} \mathrm{C}$. By the drying, the polyphenols could have interactions with other compounds or have their chemical structure changed ${ }^{[3]}$. Temperature have a negative effect on phenolic ${ }^{[21]}$. The increase in temperature also brings reductions in the vitamin $\mathrm{C}$, a thermosensitive compound ${ }^{[22]}$. In addition, the effect of the use of ethanol was clearly evidenced. The higher retention and antioxidant activity were found with the use of ethanol. Moreover, one can see that those indexes were more relevant at lower temperatures. For example, the antioxidant activity was $26.7 \%$ higher by the use of ethanol at $50{ }^{\circ} \mathrm{C}$ whereas it was $4.4 \%$ higher by the same use at $70^{\circ} \mathrm{C}$. The alcohol causes a more intense evaporation of water, reducing the time of exposure of the sample to the drying process, minimizing the effects of temperature under the quality parameters analyzed ${ }^{[23]}$.

\section{Conclusions}

The immersion in ethanol and the use of higher temperatures lead to shorter drying time. In addition, the quality compounds analyzed had greater preservation in the experiment at 50 ${ }^{\circ} \mathrm{C}$ and with application of ethanol, evidencing the importance of the use pretreatment as well as the choice of the range temperature process.

\section{Acknowledgment}

The authors gratefully acknowledge CAPES (Coordination for the Improvement of Higher Education Personnel), CNPq (National Council for Scientific and Technological Development) and FAPEMIG (State of Minas Gerais Research Foundation).

\section{References}

[1] Herbig, A.; Renard, C. M. G. C. Factors that impact the stability of vitamin C at intermediate temperatures in a food matrix. Food Chemistry 2017, 220 (1), 444-451

[2] Rodrígues-Roque, M. J., Ancos , B.; Sánches-Moreno, C.; Cano, M. P.; ElezMartínez, P.; Martín-Belloso, O. Impact of food matrix and processing on the in vitro bioaccessibility of vitamin $\mathrm{C}$, phenolic compounds, and hydrophilic antioxidant activity from fruit juice-based beverages. Journal. Functional Foods 2015, 14, 33-43.

[3] Méndez-Lagunas, L.; Rodríguez-Ramírez, J.; Cruz-Gracida, M.; Sandoval-Torres, S.; Barrida-Bernal, G. Convective drying kinetics of strawberry (Fragaria ananassa): 
effects on anti-oxidant activity, anthocyanins and total phenolic content. Food Chemistry 2017, 230 (1), 174-181.

[4] Choi, H. Impact odorants of Citrus Hallabong [(C. unshiu Marcov $\times$ C. sinensis Osbeck) $\times$ C. reticulata Blanco] cold-pressed peel oil. Journal Agricultural Food Chemistry 2003, 51 (9), 2687-2692.

[5] Song, H. S.; Phi, N. T. L.; Park, Y.; Sawamura, M. Volatile profiles in cold-pressed peel oil from Korean and Japanese Shiranui. Biosci. Biotechnol. Biochem., 2006, 70 (3), 737-739.

[6] Kumar, C.; Joardder, M. U. H.; Farrell, T. W.; Millar, G. J.; Karim, M. A. Mathematical model for intermittent microwave convective drying of food materials. Drying. Technology 2016, 34 (8), 962-973.

[7] Corrêa, J. L. G.; Rasia, M. C.; Mulet A.; Cárcel, J. A. Influence of ultrasound application on both the osmotic pretreatment and subsequent convective drying of pineapple (Ananas comosus ). Innovative Food Science and Emerging Technologies 2017, 41, 284-291.

[8] Mendonça, K. S.; Corrêa, J. L. G.; Junqueira, J. R. J.; Cirillo, M. A.; Figueira, F. V.; Carvalho, E. E. N. Influences of convective and vacuum drying on the quality attributes of osmo-dried pequi (Caryocar brasiliense Camb .) slices. Food Chemistry 2017, 224 (1), 212-218.

[9] Santos, P. H. S.; Silva, M. A. Kinetics of L-Ascorbic acid degradation in pineapple drying under ethanolic atmosphere. Drying Technology 2009, 27 (9), 37-41.

[10] Corrêa, J. L. G.; Braga, A. M. P.; Hochheim, M.; Silva, M. A. The influence of ethanol on the convective drying of unripe, ripe, and overripe bananas. Drying Technology 2012, 30 (8), 817-826.

[11] Silva, D. M.; Pires, C. R. F.; Lima, J. P.; Pereira, A. S.; Silva, C. A. Desidratação osmótica para obtenção de cagaita passa. Journal bionergy food Science 2015, 2 (4), 226-233.

[12] Garau, M. C.; Simal, S.; Femenia, A.; Rosselló, C. Drying of orange skin: drying kinetics modelling and functional properties. Journal Food Engineering 2006, 75 (2) 288-295.

[13] Lurie, S.; Pesis, E.; Gadiyeva, O.; Feygenberg, O.; Ben-Arie, R.; Kaplunov, T.; Zutahy, Y.; Lichter, A. Modified ethanol atmosphere to control decay of table grapes during storage. Postharvest Biol. Technology 2006, 42 (3), 222-227.

[14] Waterhouse, A. L. Polyphenolics: determination of total phenolics. In Current protocols in food analytical chemistry; Wrolstad, R. E., Eds.; John Wiley \& Sons Org.: New York, 2002.

[15] Strohecker, R.; Henning, H. Analisis de vitaminas: métodos comprovados; Paz Montalvo: Madrid, 1967.

[16] Rufino, F. D. S.; Alves, M. S. M.; Brito, R. E.; Morais, E. S.; Sampaio, S. M.; Jiménez, C. G.; Calixto, J. P. Metodologia científica: determinação da atividade 
antioxidante total em frutas pela captura do Radical livre ABTS; Empresa Brasileira de Pesquisa Agropecuária: Fortaleza, 2007.

[17] Alavi, S.; Ohmura, R.; Ripmeester, J. A. A molecular dynamics study of ethanolwater hydrogen bonding in binary structure I clathrate hydrate with $\mathrm{CO}_{2}$. Journal Chemistry Physical 2011, 134, 54702-54702.

[18] Wojdylo, A.; Figiel, A.; Lech, K.; Nowicka , P.; Oszmianski, J. Effect of convective and vacuum - microwave drying on the bioactive compounds , color , and antioxidant capacity of sour cherries. Journal Bioprocess Technology 2014, 7 (3), 829-841.

[19] Nascimento, E. M. G. C.; Mulet, A.; Ascheri, J. L. R.; Wanderlei, P. C.; Cárcel, J. A. Effects of high-intensity ultrasound on drying kinetics and antioxidant properties of passion fruit peel. Journal Food Engineering 2015, 170, 108-118.

[20] Junqueira, J. R. J.; Corrêa, J. L. G.; Oliveira, H. M.; Avelar, R. I. S.; Pio, L. A. S., Convective drying of cape gooseberry fruits : Effect of pretreatments on kinetics and quality parameters. Food Science Technology 2017, 82, 404-410.

[21] Acosta-Estrada, B. A.; Gutiérrez-Uribe, J. A.; Serna-Saldívar, S. O. Bound phenolics in foods , a review. Food Chemistry 2014, 152, 46-55.

[22] Saini, R. K.; Shetty, N. P.; Prakash, M. Giridhar, P. Effect of dehydration methods on retention of carotenoids, tocopherols, ascorbic acid and antioxidant activity in Moringa oleifera leaves and preparation of a RTE product. Journal Food Science Technology 2014, 51 (9) 2176-2182.

[23] Junqueira, J. R. J.; Resende, N. S.; Mendonça, K. S.; Pereira, M. C. A.; Vilas Boas, E. V. B.; Corrêa, J. L. G. Secagem a vácuo de hortaliças não convencionais pretratadas com etanol. In Proceedings Brazilian Congress of Chemical Engineering, Fortaleza, Brazil, September 25-29, 2016;1- 8. 